\title{
Circadian rhythm disorder of thrombosis and thrombolysis-related gene expression in apolipoprotein $\mathbf{E}$ knock-out mice
}

\author{
XUEQING ZHANG ${ }^{*}$, FENGDI ZHAO* , CHEN XU, CHAO LU, \\ HUIMING JIN, SIFENG CHEN and RUIZHE QIAN \\ Department of Physiology and Pathophysiology, Shanghai Medical College, \\ Fudan University, Shanghai 200032, P.R. China
}

Received March 18, 2008; Accepted May 9, 2008

DOI: $10.3892 /$ ijmm_00000002

\begin{abstract}
Plaque rupture and subsequent embolism as well as thrombosis are major causes of acute myocardial infarction and stroke secondary to atherosclerosis. Pai-1, t-PA, TF and ET-1 are thrombosis- and thrombolysis-related factors which play important roles in thrombosis formation and plaque rupture. Since acute myocardial infarction and stroke are more likely to occur between 6 a.m. and 12 p.m. than at another time of the day, we studied the relationship between circadian rhythm and Pai-1, t-PA, TF and ET-1 in normal and atherosclerotic mice. Atherosclerosis was developed in apoE $\mathrm{E}^{-/-}$mice fed a normal diet or a high cholesterol diet. The expression of Pai-1, t-PA, TF and ET-1 in the hearts of control C57BL/6J mice and atherosclerotic mice was measured by real-time RT-PCR at different Zeitgeber times (ZT) including ZT0, ZT4, ZT8, ZT10, ZT12, ZT14, ZT16 and ZT20. The expression of Pai-1, t-PA, TF and ET-1 peaked between ZT14 and ZT16 and bottomed at ZT10 in C57BL/6J mice. Their expression in apoE $\mathrm{E}^{-/}$mice fed a normal diet lost circadian rhythm. Their expression in $\mathrm{apoE}^{-/-}$mice fed a high cholesterol diet peaked at ZT4, indicating a reverse circadian rhythm. Our result indicates that circadian changes in the expression of Pai-1, t-PA, TF and ET-1 may be involved in the onset of myocardial infarction and stroke.
\end{abstract}

\section{Introduction}

Acute myocardial infarction and stroke are major complications associated with atherosclerosis. A number of studies have

Correspondence to: Dr Ruizhe Qian, Department of Physiology and Pathophysiology, Shanghai Medical College, Fudan University, P.O. Box 224, 138 Yixueyuan Road, Shanghai 200032, P.R. China E-mail: rzqian@shmu.edu.cn

${ }^{*}$ Contributed equally

Key words: circadian rhythm, atherosclerosis, thrombosis, thrombolysis, apolipoprotein $\mathrm{E}$ established a relationship between circadian rhythm and these complications. They are more likely to occur between 6 a.m. and 12 p.m. than at another time of the day $(1,2)$. Plaque rupture and subsequent embolism as well as thrombosis are the major causes of these life-threatening complications (3-6). Plaque ruptures in response to local or systemic change in the coagulation system. Several local modulators of plaque rupture are involved in coagulation (7). Both the tissue factor and tissue factor pathway inhibitor (TFPI) are expressed in advanced human atherosclerotic lesions and are abundant at sites of plaque rupture (8). The factors in the fibrinolytic system such as tissue plasminogen activator (t-PA) and plasminogen activator inhibitor (PAI), increase in advanced human plaques (9). For a systemic perspective, increased plasma levels of PAI-1 (10), tissue factor (11) and tissue plasminogen activator (12) indicate an increased risk of cardiovascular events. In addition, the mechanical stress acting on the plaque and vessel wall plays an important role in plaque rupture (13). For example, endothelin-1 (ET-1) may increase the vessel tone and cause plaque rupture (14).

The present study therefore aimed to explore whether and how Pai-1, t-PA, TF and ET-1 are related to the circadian rhythm in atherosclerotic mice.

\section{Materials and methods}

Animals and diet. Twenty-four male C57BL/6J mice $\sim 12$ weeks old were purchased from Shanghai Laboratory Animal Center of the Chinese Academy of Science. Forty-eight male apoE knock-out mice $\sim 12$ weeks old were purchased from the Department of Laboratory Animal Science Animals of Peking University Health Science Center. The mice were maintained in a daily 12:12 light/dark cycle for 4 weeks. C57BL/6J mice were fed with a normal chow diet. ApoE ${ }^{-/-}$ mice were divided into two groups and fed a normal chow diet and a western-type diet (containing $0.15 \%$ cholesterol and $21 \%$ fat), respectively. According to Zeitgeber time (ZT) (ZT0 is defined as lights-on time and ZT12 as lights-off time), mice were sacrificed at different time points including ZT0, ZT4, ZT8, ZT10, ZT12, ZT14, ZT16 and ZT20. All animal experiments were carried out based on the criteria of the Medical Laboratory Animal Administrative Committee of Shanghai. 
Table I. Primer pairs used to amplify PCR products.

\begin{tabular}{llccc}
\hline Gene & \multicolumn{1}{c}{ Forward primer(5'-3') } & Product size & $\begin{array}{c}\text { Annealing } \\
\text { temperature }\end{array}$ & $\begin{array}{c}\text { GenBank } \\
\text { accession no. }\end{array}$ \\
\hline t-PA & $\begin{array}{l}\text { Forward: TGACCAGGGAATACATGGGAG } \\
\text { Reverse: CTGAGTGGCATTGTACCAGGC }\end{array}$ & $176 \mathrm{bp}$ & $60^{\circ} \mathrm{C}$ & NM_008872 \\
Pai-1 & $\begin{array}{l}\text { Forward: CAAGCTCTTCCAGACTATGGTG } \\
\text { Reverse: CACTGAAGTAGAGGGCATTCAC }\end{array}$ & $176 \mathrm{bp}$ & $65^{\circ} \mathrm{C}$ & NM_008871 \\
TF & $\begin{array}{l}\text { Forward: GGACAGCCAGTAATTCAGCAG } \\
\text { Reverse: GCTTGAGCCTTTCCGATAATAA }\end{array}$ & $162 \mathrm{bp}$ & $65^{\circ} \mathrm{C}$ & NM_010171 \\
ET-1 & $\begin{array}{l}\text { Forward: GCACCGGAGCTGAGAATGG } \\
\text { Reverse: GTGGCAGAAGTAGACACACTC }\end{array}$ & $119 \mathrm{bp}$ & $65^{\circ} \mathrm{C}$ & NM_010104 \\
GAPDH & $\begin{array}{l}\text { Forward: ACAGCCGCATCTTCTTGTGCAGTG } \\
\text { Reverse: GGCCTTGACTGTGCCGTTGAATTT }\end{array}$ & $226 \mathrm{bp}$ & $55^{\circ} \mathrm{C}$ & BC_083149 \\
\hline
\end{tabular}

Lillie-Ashburnes Oil Red O staining. Mice were deeply anesthetized with $20 \%$ ethyl carbamate. The aorta root and heart were rapidly isolated. For frozen sections, the arch of each aorta was removed, stored in buffered formalin (10\%) and dehydrated in $20 \%$ sucrose solution. Then the aortic segments were embedded in OCT. Cross-sectional serial sections with a $20-\mu \mathrm{m}$ thickness were prepared for staining. Lillie-Ashburnes oil red $\mathrm{O}$ staining was used to show atherosclerotic plaques.

RNA isolation and real-time PCR. The heart was harvested, frozen in liquid nitrogen and stored at $-70^{\circ} \mathrm{C}$ until RNA isolation. Total RNA was extracted using Trizol Reagent (Invitrogen, Carlsbad, CA). Two micrograms of total RNA were reversely transcribed and amplified using the RevertAId $^{\text {TM }}$ First Strand cDNA Synthesis kit (Fermentas, Burlington, Canada). The relative mRNA level was measured by real-time PCR using SYBR-Green Realtime PCR Master Mix (Toyobo, Osaka, Japan) with SYBR-Green I. Specific primer pairs for t-PA, Pai-1, TF or ET-1 were designed based on published data in GenBank and are listed in Table I.

Statistical analysis. Data are expressed as the means \pm SEM and evaluated by one-way ANOVA analysis and the GamesHowell post-test using SPSS 11.5 software. A probability value $<0.05$ was considered statistically significant.

\section{Results}

Formation of atheromatous plaque in the aorta of apoE knock-out mice. Lillie-Ashburnes Oil Red O staining of frozen sections showed no obvious plaque in the aorta root of apoE $\mathrm{E}^{-/}$ mice fed a normal chow diet although foam cells were observed under the endothelium. Obvious atheromatous plaques were observed in the aorta root of apoE $\mathrm{E}^{-/-}$mice fed a high cholesterol diet for 4 weeks. Oil Red O staining showed obvious lipid depositions in the plaques (Fig. 1).

Daily expression of $t-P A, P a i-1$ and TF $m R N A$. The t-PA mRNA in C57BL/6J mice peaked at ZT14 $(\mathrm{P}<0.01$, between ZT0 and ZT14). In apoE $\mathrm{E}^{-/-}$mice fed a normal diet, an animal model of the early stage of atherosclerosis, the t-PA expression showed no significant daily circadian rhythm $(\mathrm{P}>0.05)$. In apoE ${ }^{-/-}$mice fed a high cholesterol diet, however, the circadian rhythm of t-PA mRNA reversed. The expression of t-PA peaked at ZT4 $(\mathrm{P}<0.01$ between ZT4 and ZT20) instead of ZT14. At ZT4, the t-PA in the heart of apoE $\mathrm{E}^{-/-}$mice fed with a western-type diet was higher than in other groups. In contrast, at ZT14, t-PA in C57BL/6J mice was highest (Fig. 2).

The circadian rhythm of Pai- 1 in the hearts of C57BL/6J mice oscillated (Fig. 3) with a clear peak at ZT14 (P<0.01 between ZT0 and ZT14). However, no significant daily fluctuation was observed in apoE $\mathrm{E}^{-/}$mice fed a normal diet Similar to t-PA, Pai-1 in apoE $\mathrm{E}^{-/-}$mice fed a western-type diet was highest at ZT4. At ZT0, Pai-1 mRNA level in apoE ${ }^{-/-}$ mice fed with a western-type diet was higher than that in C57BL/6J mice $(\mathrm{P}<0.05)$ or apoE $\mathrm{E}^{-/}$mice fed a normal diet $(\mathrm{P}<0.01)$. At ZT8, ZT14 and ZT16, $\mathrm{ApoE}^{-/-}$mice fed a normal diet expressed less $(\mathrm{P}<0.05)$ Pai-1 than $\mathrm{C} 57 \mathrm{BL} / 6 \mathrm{~J}$ mice or apoE $\mathrm{E}^{-/}$mice fed a western-type diet. The circadian rhythm curves of $\mathrm{C} 57 \mathrm{BL} / 6 \mathrm{~J}$ mice and apoE $\mathrm{E}^{-/-}$mice fed crossed between ZT10 and ZT12.

The rhythmic expression of the TF gene in the hearts of C57BL/6J mice peaks at ZT14. In the hearts of apoE $\mathrm{E}^{-/-}$mice fed a normal diet or a western-type diet, TF circadian expression peaked at ZT20 $(\mathrm{P}<0.05$ between ZT4 and ZT 20) and ZT4 $(\mathrm{P}<0.01$ between ZT4 and ZT20), respectively. At ZT4, TF expression in apoE $\mathrm{E}^{-/}$mice fed a normal diet was highest while at ZT14, TF expression in C57BL/6J mice was highest. At ZT10, ZT12, ZT16 and ZT20, apoE-/- mice fed a western-type diet showed a reduction in the mRNA expression level when compared with that in $\mathrm{C} 57 \mathrm{BL} / 6 \mathrm{~J}$ mice (Fig. 4).

Daily expression of ET-1 mRNA. A significant circadian rhythm of ET-1 expression was observed in the hearts of all three groups with peaks at ZT16 in C57BL/6J mice, ZT14 in apoE ${ }^{-/-}$ mice fed a normal diet and ZT4 in apoE ${ }^{-/}$mice fed a westerntype diet. At ZT16, ET-1 expression levels stratified from high to low were found in $\mathrm{C} 57 \mathrm{BL} / 6 \mathrm{~J}$ mice, apoE $\mathrm{E}^{-/-}$mice fed a normal diet and apoE $\mathrm{E}^{-/-}$mice fed a western-type diet; while at ZT4, the order was reversed (Fig. 5). 

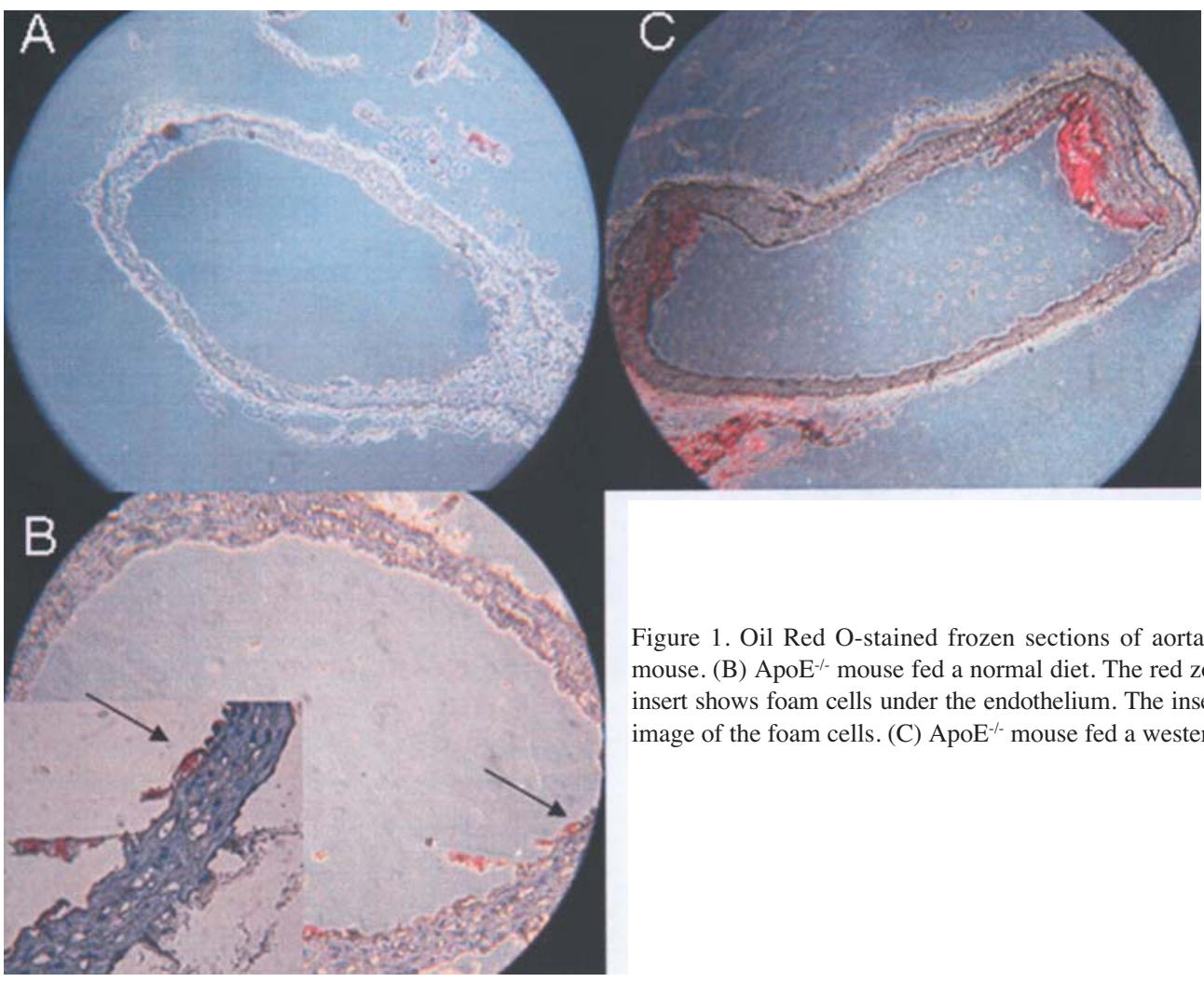

Figure 1. Oil Red O-stained frozen sections of aorta root. (A) C57BL/6J mouse. (B) $\mathrm{ApoE}^{-/-}$mouse fed a normal diet. The red zone in the rectangular insert shows foam cells under the endothelium. The insert shows a magnified image of the foam cells. (C) $\mathrm{ApoE}^{-/-}$mouse fed a western-type diet.

\section{Circadian expression changes of t-PA mRNA}

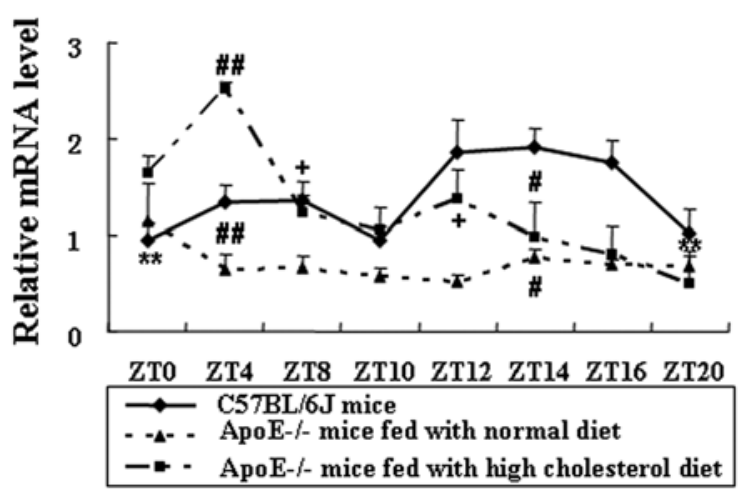

Figure 2. Daily fluctuation of t-PA mRNA in the heart of C57BL/6J and apoE $E^{-/-}$mice. The mRNA level of t-PA was normalized to GAPDH mRNA. The value at ZT0 for $\mathrm{C} 57 \mathrm{BL} / 6 \mathrm{~J}$ mice was defined as 1 . Values represent the mean \pm SEM ( $n=3$ per time point). ${ }^{* *} \mathrm{P}<0.01$ vs ZT14 in C57BL/6J mice; ${ }^{* *} \mathrm{P}<0.01$ vs $\mathrm{ZT} 4$ in apoE ${ }^{-/}$mice fed a western-type diet. ${ }^{\#} \mathrm{P}<0.01$ and ${ }^{\#} \mathrm{P}<0.05$ vs $\mathrm{C} 57 \mathrm{BL} / 6 \mathrm{~J}$ mice; ${ }^{+} \mathrm{P}<0.05$ vs apoE ${ }^{-/-}$mice fed a normal diet.

\section{Discussion}

Myocardial infarction and stroke are severe complications secondary to atherosclerosis that claim a significant number of lives each year. Local and systemic coagulation disorders are responsible for atherosclerotic plaque ruptures causing these complications. ApoE $E^{-/-}$mice fed with either a normal diet or a western-type diet are proven animal models of atherosclerosis. Our results showed that obvious atheromatous plaque formed in 3-month male apoE $\mathrm{E}^{-/}$mice fed a westerntype diet for 4 weeks. Three-month male $\mathrm{apoE}^{-/-}$mice fed a

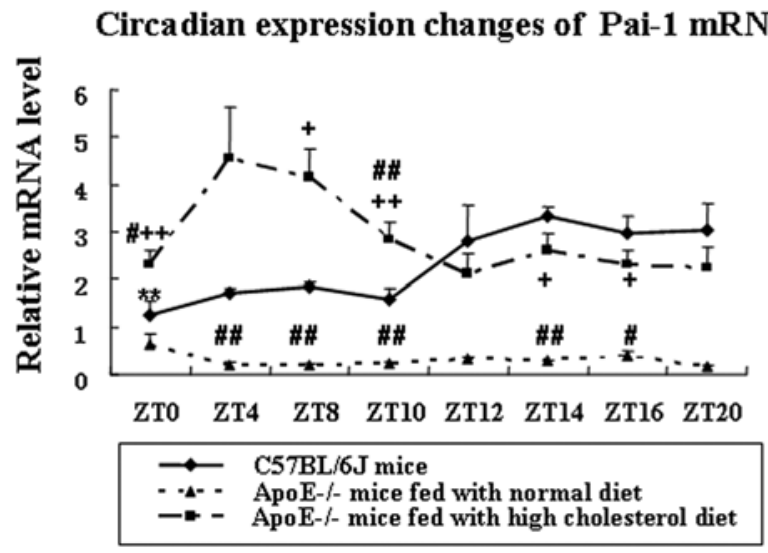

Figure 3. Daily fluctuation of Pai-1 mRNA in the heart of C57BL/6J and apoE ${ }^{-/-}$mice. The mRNA level of Pai-1 was normalized to GAPDH mRNA. The value at ZT0 for $\mathrm{C} 57 \mathrm{BL} / 6 \mathrm{~J}$ mice was defined as 1 . Values represent the mean \pm SEM ( $\mathrm{n}=3$ per time point). ${ }^{* *} \mathrm{P}<0.01$ vs ZT14 in $\mathrm{C} 57 \mathrm{BL} / 6 \mathrm{~J}$ mice. ${ }^{\# \#} \mathrm{P}<0.01$ and ${ }^{\#} \mathrm{P}<0.05$ vs $\mathrm{C} 57 \mathrm{BL} / 6 \mathrm{~J}$ mice; ${ }^{++} \mathrm{P}<0.01$ and $+\mathrm{P}<0.05 \mathrm{vs} \mathrm{apoE}^{-1-}$ mice fed a normal diet.

normal diet for 4 weeks meanwhile, had no obvious plaque although many foam cells were observed under the endothelium. Studies showed that atheromatous plaque formation started at 5-6 weeks and formed obvious fibrous plaque at 20 weeks in apoE ${ }^{-/}$mice fed a normal diet (15). Therefore, in our investigation, apoE $\mathrm{E}^{-/}$mice fed a normal diet for 4 weeks were at the early stage of atherosclerosis. ApoE $\mathrm{E}^{-/}$mice fed a western-type diet for 4 weeks were considered to be at the advanced stage of atherosclerosis.

The biological clock composes several positive and negative transcriptional-translational feedback loops 


\section{Circadian expression changes of TF mRNA}

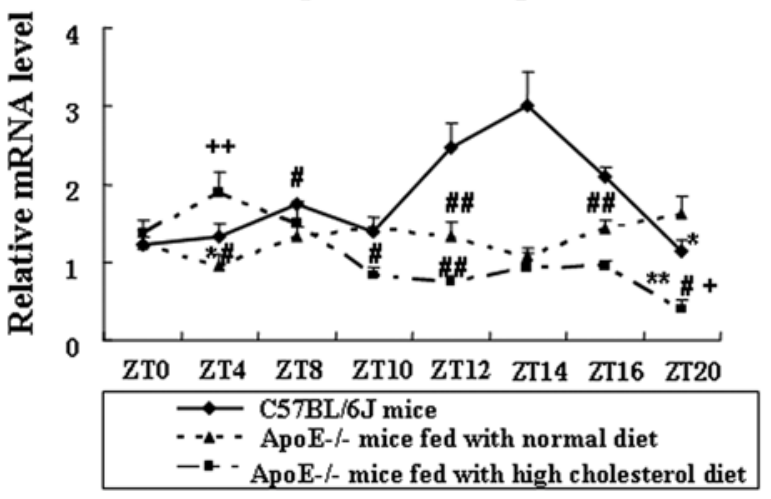

Figure 4. Daily fluctuation of tissue factor mRNA in the heart of C57BL/6 and $\mathrm{apoE}^{-/}$mice. The tissue factor (TF) mRNA levels were normalized to GAPDH mRNA. The value at ZT0 for C57BL/6J mice was defined as 1 . Values represent the mean \pm SEM $\left(n=3\right.$ per time point). ${ }^{*} \mathrm{P}<0.05$ vs $Z \mathrm{ZT} 14$ in C57BL/6J mice; ${ }^{*} \mathrm{P}<0.05$ vs ZT20 in apoE ${ }^{-/}$mice fed a normal diet; ${ }^{* *} \mathrm{P}<0.01$ vs ZT4 in apoE ${ }^{-/}$mice fed a western-type diet. ${ }^{\# \#} \mathrm{P}<0.01$ and ${ }^{~} \mathrm{P}<0.05$ vs C57BL/6J mice; ${ }^{++} \mathrm{P}<0.01$ and ${ }^{+} \mathrm{P}<0.05 \mathrm{vs} \mathrm{apoE}^{-/-}$mice fed a normal diet.

including the genes Per, Bmal1, Clock, Cry, Rev-Erb $\alpha$ and CKIE (16). The biological clock is thought to be located in the suprachiasmatic nucleus (SCN) of the hypothalamus (17) and peripheral tissues. The rhythm of the peripheral clock is regulated directly or indirectly by various neural, humoral and other signaling molecules under the control of the central clock in SCN (18). In addition to clock genes, many other genes show circadian oscillations and are called clockcontrolled genes. There are more than 400 genes expressed rhythmically in the hearts of mice (19). Circadian clock genes and clock-controlled genes change in various animal models of cardiovascular disorders. Phase alterations of the clock genes in the heart (bmal1, per2) were demonstrated in streptozotocin-induced diabetic rats (20). In the rat heart with pressure-overload hypertrophy (21), circadian expression of clock-controlled genes (dbp, anp) is significantly reduced.

Myocardial infarction and stroke are more likely to occur in early morning. It may result from the circadian variation in fibrinolytic activity. The circadian fluctuation of fibrinolytic activity, which has lower activity in the morning and higher activity in the evening, has been observed in both healthy individuals and patients with acute or chronic coronary artery disease (22-24). PAI-1 is one of the major inhibitors of fibrinolysis $(23,25)$. In the present experiments, we found a clear daily oscillation of Pai-1 gene expression in the hearts of $\mathrm{C} 57 \mathrm{BL} / 6 \mathrm{~J}$ mice with peaks at night. In advanced atherosclerosis, the daily fluctuation reversed. The disorder of the circadian rhythm may result from the changes in atherosclerotic development. In daytime, the Pai-1 expression in apoE $^{-/}$mice fed a western-type diet was significantly higher than that in other groups. The result indicated that increased Pai-1 mRNA levels may contribute to more frequent morning occurrences of myocardial infarction and stroke.

t-PA is an important factor in the fibrinolytic system. It also showed a clear daily oscillation in the heart of C57BL/6J and $\mathrm{apoE}^{-/-}$mice fed a western-type diet, but no circadian rhythm in the heart of $\mathrm{apoE}^{-/}$mice fed a normal diet. The

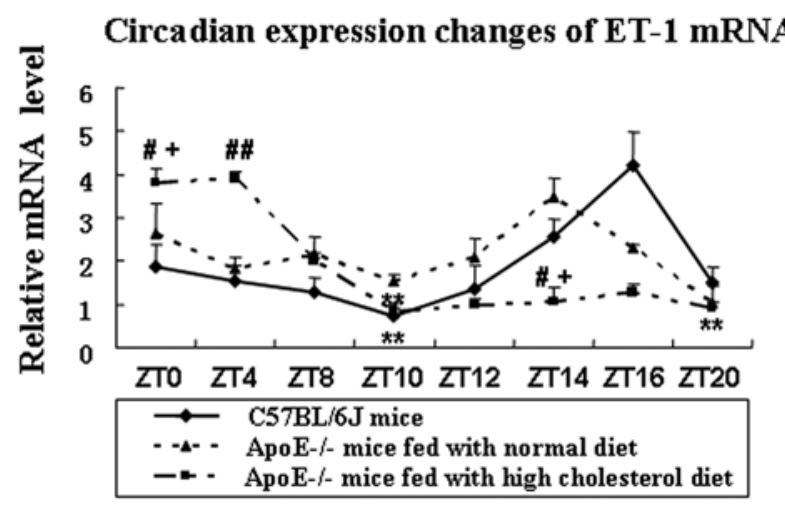

Figure 5. Daily fluctuation of endothelin-1 mRNA in hearts. The endothelin-1 (ET-1) mRNA levels were normalized to GAPDH mRNA. The value at ZT0 for $\mathrm{C} 57 \mathrm{BL} / 6 \mathrm{~J}$ mice was normalized to 1 . Values represents the mean $\pm \mathrm{SEM}$ $(\mathrm{n}=3$ per time point) and were assessed by one-way ANOVA analysis. ${ }^{* *} \mathrm{P}<0.01$ vs ZT16 in C57BL/6J mice; ${ }^{* *} \mathrm{P}<0.01$ vs ZT14 in apoE-/- mice fed a normal diet; ${ }^{* *} \mathrm{P}<0.01$ vs $\mathrm{ZT} 4$ in apoE $\mathrm{E}^{-/-}$mice fed a western-type diet. ${ }^{\# \#} \mathrm{P}<0.01$ and ${ }^{\#} \mathrm{P}<0.05$ vs $\mathrm{C} 57 \mathrm{BL} / 6 \mathrm{~J}$ mice; ${ }^{+} \mathrm{P}<0.05$ vs apoE ${ }^{-/-}$mice fed a normal diet.

difference between apoE $\mathrm{E}^{-/}$mice fed with different diets in the morning (mainly at ZT4) indicated that a high cholesterol/fat diet may increase the expression of the t-PA gene. Pai-1 and t-PA play opposite roles in fibrinolytic activity. Further effort should be devoted to study the interaction of Pai-1 and $\mathrm{t}-\mathrm{PA}$ in atherosclerosis.

$\mathrm{TF}$ is an essential initiator of the coagulation cascade expressed in various stages of atherosclerotic lesions (26). It is an important determinant of thrombogenicity which contributes to fibrin-rich thrombus formation after plaque disruption and contributes to the progression of atherosclerotic lesions (27-29). In the present study, we found a clear circadian rhythm in the hearts of all three groups. The amount and circadian rhythm of TF in atherosclerotic mice changed significantly, indicating its role in plaque rupture.

Active plaques show a locally enhanced vasoreactivity. Enhanced production of active ET-1 may contribute to the increased tone of vessels with advanced plaques or even very early atherosclerotic lesions (14). Hanai et al (30) found that the ET-1 gene tends to express in rat heart during the night. We confirmed ET-1 rhythmic expression in C57BL/6J mice with a peak at night (ZT16). Its level in atherosclerotic mice decreased in the dark and increased under light. The robust expression increase in the morning in the atherosclerotic mice fed a western-type diet may explain why more cardiovascular events happen in the morning.

In summary, we found that the expression and circadian rhythm of Pai-1, t-PA, TF and ET-1 changed in atherosclerotic mice. The result indicates a role of thrombotic and fibrinolytic factors in the development of atherosclerosis, subsequent plaque rupture and even the onset of myocardial infarction. Further investigations should be conducted to unveil the profound mechanism.

\section{Acknowledgements}

This work was supported by grants from the National Natural Science Foundation of China (30771003) and the Natural Science Foundation of Shanghai (07ZR14009). 


\section{References}

1. Muller JE, Stone PH, Turi ZG, Rutherford JD, Czeisler CA, Parker C, et al: Circadian variation in the frequency of onset of acute myocardial infarction. N Engl J Med 313: 1315-1322, 1985.

2. Tanaka A, Kawarabayashi T, Fukuda D, Nishibori Y, Sakamoto T, Nishida Y, et al: Circadian variation of plaque rupture in acute myocardial infarction. Am J Cardiol 93: 1-5, 2004.

3. Constantinides P: Coronary thrombosis linked to fissure in atherosclerotic vessel wall. JAMA 188 (Suppl): 35-37, 1964.

4. Davies MJ and Thomas A: Thrombosis and acute coronaryartery lesions in sudden cardiac ischemic death. N Engl J Med 310: 1137-1140, 1984.

5. DeWood MA, Spores J, Notske R, Mouser LT, Burroughs R, Golden MS, et al: Prevalence of total coronary occlusion during the early hours of transmural myocardial infarction. N Engl J Med 303: 897-902, 1980.

6. Richardson PD, Davies MJ and Born GV: Influence of plaque configuration and stress distribution on fissuring of coronary atherosclerotic plaques. Lancet 2: 941-944, 1989.

7. Khrenov AV, Ananyeva NM, Griffin JH and Saenko EL: Coagulation pathways in atherothrombosis. Trends Cardiovasc Med 12: 317-324, 2002.

8. Kaikita K, Takeya M, Ogawa H, Suefuji H, Yasue H and Takahashi K: Co-localization of tissue factor and tissue factor pathway inhibitor in coronary atherosclerosis. J Pathol 188: 180-188, 1999.

9. Falkenberg M, Tjarnstrom J, Ortenwall P, Olausson $\mathrm{M}$ and Risberg B: Localization of fibrinolytic activators and inhibitors in normal and atherosclerotic vessels. Thromb Haemost 75 933-938, 1996.

10. Nordt TK, Peter K, Ruef J, Kubler W and Bode C: Plasminogen activator inhibitor type-1 (PAI-1) and its role in cardiovascular disease. Thromb Haemost 82 (Suppl 1): 14-18, 1999.

11. Smilde TJ, van Wissen S, Wollersheim H, Trip MD, Kastelein JJ and Stalenhoef AF: Effect of aggressive versus conventional lipid lowering on atherosclerosis progression in familial hypercholesterolaemia (ASAP): a prospective, randomised, doubleblind trial. Lancet 357: 577-581, 2001.

12. Thogersen AM, Jansson JH, Boman K, Nilsson TK, Weinehall L, Huhtasaari F, et al: High plasminogen activator inhibitor and tissue plasminogen activator levels in plasma precede a first acute myocardial infarction in both men and women: evidence for the fibrinolytic system as an independent primary risk factor. Circulation 98: 2241-2247, 1998.

13. Zaman AG, Helft G, Worthley SG and Badimon JJ: The role of plaque rupture and thrombosis in coronary artery disease. Atherosclerosis 149: 251-266, 2000.

14. Ihling C, Bohrmann B, Schaefer HE, Technau-Ihling K and Loeffler BM: Endothelin-1 and endothelin converting enzyme-1 in human atherosclerosis - novel targets for pharmacotherapy in atherosclerosis. Curr Vasc Pharmacol 2: 249-258, 2004.
15. Breslow JL: Mouse models of atherosclerosis. Science 272 : 685-688, 1996.

16. Fu L and Lee CC: The circadian clock: pacemaker and tumour suppressor. Nat Rev Cancer 3: 350-361, 2003.

17. Schibler U: The daily rhythms of genes, cells and organs Biological clocks and circadian timing in cells. EMBO Rep 6: S9-S13, 2005.

18. Hirota $\mathrm{T}$ and Fukada $\mathrm{Y}$ : Resetting mechanism of central and peripheral circadian clocks in mammals. Zoolog Sci 21: 359-368, 2004.

19. Storch KF, Lipan O, Leykin I, Viswanathan N, Davis FC, Wong WH, et al: Extensive and divergent circadian gene expression in liver and heart. Nature 417: 78-83, 2002.

20. Young ME, Wilson CR, Razeghi P, Guthrie PH and Taegtmeyer H: Alterations of the circadian clock in the heart by streptozotocininduced diabetes. J Mol Cell Cardiol 34: 223-231, 2002.

21. Young ME, Razeghi $\mathrm{P}$ and Taegtmeyer H: Clock genes in the heart: characterization and attenuation with hypertrophy. Circ Res 88: 1142-1150, 2001.

22. Angleton P, Chandler WL and Schmer G: Diurnal variation of tissue-type plasminogen activator and its rapid inhibitor (PAI-1). Circulation 79: 101-106, 1989.

23. Huber K, Rosc D, Resch I, Schuster E, Glogar DH, Kaindl F, et al: Circadian fluctuations of plasminogen activator inhibitor and tissue plasminogen activator levels in plasma of patients with unstable coronary artery disease and acute myocardial infarction. Thromb Haemost 60: 372-376, 1988.

24. Kluft C, Jie AF, Rijken DC and Verheijen JH: Daytime fluctuations in blood of tissue-type plasminogen activator (t-PA) and its fast-acting inhibitor (PAI-1). Thromb Haemost 59: 329-332, 1988.

25. Andreotti F, Davies GJ, Hackett DR, Khan MI, De Bart AC, Aber VR, et al: Major circadian fluctuations in fibrinolytic factors and possible relevance to time of onset of myocardial infarction, sudden cardiac death and stroke. Am J Cardiol 62: 635-637, 1988.

26. Marutsuka K, Hatakeyama K, Yamashita A and Asada Y: Role of thrombogenic factors in the development of atherosclerosis. J Atheroscler Thromb 12: 1-8, 2005.

27. Hatakeyama K, Asada Y, Marutsuka K, Kataoka H, Sato Y and Sumiyoshi A: Expression of tissue factor in the rabbit aorta after balloon injury. Atherosclerosis 139: 265-271, 1998.

28. Hatakeyama K, Asada Y, Marutsuka K, Sato Y, Kamikubo Y and Sumiyoshi A: Localization and activity of tissue factor in human aortic atherosclerotic lesions. Atherosclerosis 133: 213-219, 1997.

29. Wilcox JN, Smith KM, Schwartz SM and Gordon D: Localization of tissue factor in the normal vessel wall and in the atherosclerotic plaque. Proc Natl Acad Sci USA 86: 2839-2843, 1989.

30. Hanai S, Masuo Y, Shirai H, Oishi K, Saida K and Ishida N: Differential circadian expression of endothelin-1 mRNA in the rat suprachiasmatic nucleus and peripheral tissues. Neurosci Lett 377: 65-68, 2005. 